\title{
Lymphocytopenia and Cytotoxic Therapy in Patients with Advanced Ovarian Cancer
}

\author{
Alexei N. Shoutko ${ }^{1}$, Ludmila E. Yurkova ${ }^{2}$, Kseniya S. Borodulya ${ }^{2}$, Ludmila P. Ekimova ${ }^{1}$ \\ ${ }^{1}$ Laboratory of the development of radiation therapy methods, Federal Scientific Centre for Radiology and Surgical Technologies, Saint- \\ Petersburg, Russian Federation \\ ${ }^{2}$ Division of Gynecologic Oncology, Federal Scientific Centre for Radiology and Surgical Technologies, Saint-Petersburg, Russian \\ Federation
}

\section{Email address:}

shoutko@inbox.ru (A. N. Shoutko), yurkova_ludmila@pochta.ru (L. E. Yurkova), kaktusveg@gmail.ru (K. S. Borodulya), lupek49@mail.ru (L. P. Ekimova)

\section{To cite this article:}

Alexei N. Shoutko, Ludmila E. Yurkova, Kseniya S. Borodulya, Ludmila P. Ekimova. Lymphocytopenia and Cytotoxic Therapy in Patients with Advanced Ovarian Cancer. Cancer Research Journal. Vol. 3, No. 3, 2015, pp. 47-51. doi: 10.11648/j.crj.20150303.11

\begin{abstract}
The relationship between 5-year survival and the mean number of circulating lymphocytes during 1 month after beginning a combined therapy was investigated in 175 patients with advanced epithelial ovarian cancer to understand why myelosuppression caused by a cytotoxic treatment is almost inseparable from its benefit. Patients received a combined therapy consisting of primary cytoreductive surgery followed by different systemic treatments according to three schemes: conventional chemotherapy with cisplatinum and cyclophosphanum (CP), conventional chemotherapy with paclitaxel and carboplatinum (TP), or lower-half body irradiation (LHBI). The TP scheme included premedication with dexamethasone. The LHBI involve irradiation with a total dose of 9 Gy (3 Gy daily) in patients with primary disease. LHBI with a total dose of 1 Gy (0.1 Gy daily) was used for patients with primary disease or relapse. The LHBI treatment included five final courses of thiophosphamide/5-fluorouracil for patients with primary cancer or conventional local radiotherapy up to a total dose of 30 Gy (2 Gy daily) for relapsed patients. Survival curves were analyzed by exponential approximation, and 5-year exponential mortality rates were calculated. The mortality rates were compared with the relative decline in the mean number of circulating lymphocytes after 1 month of therapy. If pretreatment lymphocytopenia did not exceed $0.710^{9}$ cells $/ \mathrm{L}$, a linear dependency of the exponential death rate from the relative deviation of cells in the range of 1.16 to $0.7(p<0.001)$ was observed. The inevitable side effect of cytotoxic cancer therapy in the form of lymphocytopenia sheds doubt on the actual existence of effective antineoplastic immunity; however, it provides a logical background of the morphogenic function of some circulating mononuclear cells in relation to proliferating tissues, including malignant tissues.
\end{abstract}

Keywords: Cytotoxic Therapy, Death Rates, Lymphocytopenia, Myelosuppression, Ovarian Cancer, Survival

\section{Introduction}

Myelosuppression accompanies palliative chemotherapy and radiotherapy [1]. Myelosuppression occurs in $85 \%$ to $89 \%$ of patients in response to a number of basic antineoplastic drugs $[2,3]$. Patients with cancer often have moderate lymphocytopenia (up to $0.510^{9}$ cells $/ \mathrm{L}$ ), which is comparable with people who survived nuclear bomb attack [1, 4]. Such consequences of cancer therapy are not associated with the essential role of antineoplastic immunity or of metastatic spread throughout the blood and lymphatic nodes, which are the centers of the prospective protective cells. Theoretically, these difficulties are easily eliminated by accepting an alternative feeding strategy, such as supporting the function of circulating mononuclear cells to regenerate any rapidly growing tissues, including malignant tissues $[5,6$, $7,8]$. According to this alternative point of view, a cytotoxic agent damages the majority of normal cells in rapidly renewing hematopoietic and other tissues. This reparable damage chemoattracts the circulating feeding cells and weakens their participation in the maintenance of tumor growth. After recovery of the extensive somatic damage caused by the of systemic therapy, the morphogenic potential of bone marrow and blood cells is restored partially and targets malignant tissue again because of its quasi-embryonic nature. Thus, so-called "partial remission" or "complete remission" arises temporarily. To test such an alternative idea 
about the mechanism of action of systemic (nonselective) therapy, it is necessary to explore the relationship between the lymphoproliferative status of patients and the outcomes of different systemic treatments. We investigated this relationship in patients with widely spreading ovarian cancer using 5-year survival rates and the degree of lymphocytopenia in response to different cytotoxic chemotherapeutic regimens with and without lower-half body irradiation (LHBI) at non-tumoricidal doses.

\section{Methods}

The study was conducted at the Russian Scientific Center for Radiology and Surgical Technology (RSCRST) in Saint Petersburg, a comprehensive cancer center of the Ministry of Health Research, Russia. In total, 175 patients with stage IV advanced epithelial ovarian cancer or relapsed disease were attending the RSCRST for treatment between the winters of 1990 and 2010. They received a combined therapy (surgery and systemic cytostatic treatment). All patients were divided into two groups. Group A included two subgroups of patients with primary cancer who received systemic chemotherapy with cisplatinum and cyclophosphanum (subgroup $\mathrm{A}_{\mathrm{CP}}$ ) or paclitaxel, carboplatinum, and dexamethasone as a premedication (subgroup $A_{T P}$ ). Patients in Group B received systemic therapy in the form of LHBI according to technology developed in the 1990s as consolidation therapy for patients with gastrointestinal tumors, Ewing's sarcoma, breast cancer, carcinoma of the lung, and others [9]. Group B comprised four subgroups treated with fractionated LHBI: patients with primary cancer were irradiated with 3 Gy daily up to a total dose of 9 Gy (subgroup B $9 \mathrm{~Gy}$ ); those irradiated with 0.1 Gy daily up to a total dose of 1 Gy (subgroup B 1Gy ); patients with relapse treated with 0.1 Gy daily up to a total dose of 1 Gy (subgroup $\mathrm{Br}_{1 \mathrm{~Gy}}$ ); and those irradiated with 0.1 Gy daily up to a total dose of $1 \mathrm{~Gy}$, followed by conventional local radiotherapy of 2 Gy daily up to a total dose of $30 \mathrm{~Gy}$ (subgroup $\mathrm{Br}_{1 \mathrm{~Gy}+\mathrm{LRT}}$ ) without a rest interval. All patients in Group B were treated with five final courses of thiophosphamide/5-fluorouracil.

Peripheral blood testing was performed weekly, and survival during at least 5 years was recorded at a mean frequency of 3 to 4 months since the patients began combined therapy. Informed consent was obtained from all participants. All data were analyzed retrospectively.

Survival curves were generated for each subgroup using exponential curve fitting in Excel [10] and the rate constant (k) using the following equation:

$$
\mathrm{S}_{\mathrm{t}}=\mathrm{e}^{-\mathrm{kt}}
$$

where $S_{t}$ is the proportion of surviving patients at any moment during the 60 -month period, $\mathrm{t}$ is time in months after beginning therapy, and $\mathrm{k}$ is the mean exponential mortality rate during 1 month of the extended 60-month period.

The coefficient of determination $\left(\mathrm{R}^{2}\right)$ was used to determine how close the data fit a regression line. The validity of the $\mathrm{R}^{2}$ value was assessed using a goodness-of-fit function. A t-test regression was used to confirm the Rvalues [11]:

$$
t=\sqrt{ }\left[R^{2}(n-2):\left(1-R^{2}\right)\right]
$$

The mean numbers of lymphocytes and their standard error were compared with Student's $t$-test.

\section{Results}

\subsection{Mortality Rate (k)}

The k-value in Eq. 1 characterizes the exponential monthly mortality rate during the 5-year period after starting treatment. An example of the k calculation is given in Figure 1.

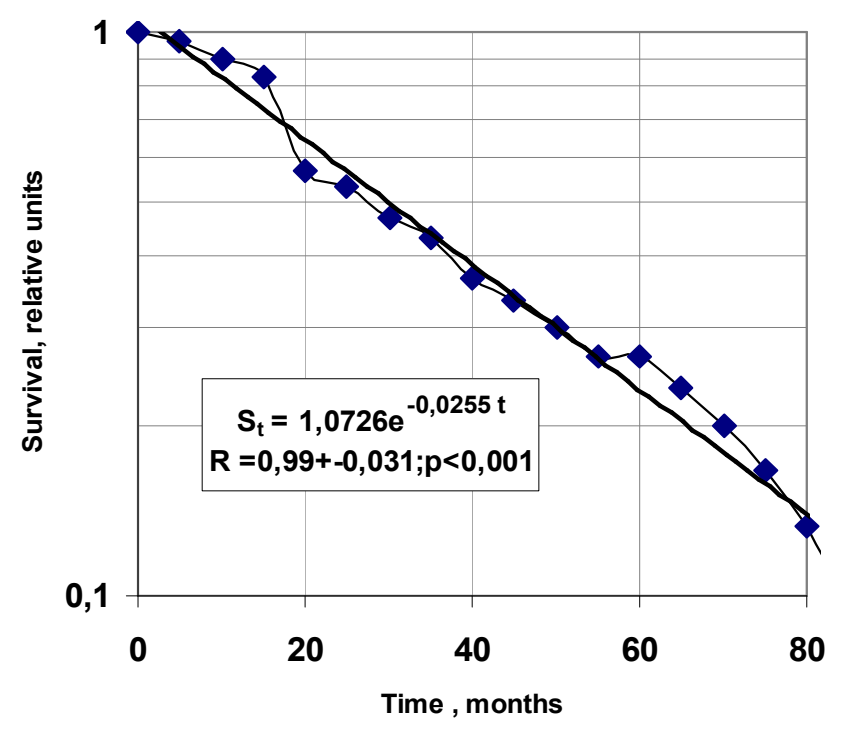

Fig. 1. Exponential approximation of a semi-logarithmic survival curve ( $x$, time in months after starting treatment; $y$, survival in relative units). The exponential relationship is shown in the panel.

The k-values calculated for the subgroups and the coefficients of determination are shown in Table 1.

Table 1. Exponential mortality rates $\left(k\right.$, month $\left.^{-1}\right)$, coefficients of approximation $(R)$ with probability values $(p)$, and median (months) survival curves in the subgroups that received chemotherapy (A) or subtotal radiotherapy $(B)$.

\begin{tabular}{lllll}
\hline Subgroups & k, month-1 & $\mathbf{R} \pm \mathbf{m R}$ & p for $\mathbf{R}$ & Median, months \\
\hline B 9 Gy & 0.01 & $0.97 \pm 0.068$ & $<0.001$ & $0 \dagger+69=69$ \\
ACP & 0.026 & $0.99 \pm 0.031$ & $<0.001$ & $3 \dagger+27=30$ \\
B 1 Gy & 0.029 & $0.97 \pm 0.076$ & $<0.001$ & $0 \dagger+24=24$ \\
Br 1 Gy & 0.043 & $0.93 \pm 0.098$ & $<0.001$ & $0 \dagger+16=16$ \\
ATP & 0.051 & $0.98 \pm 0.078$ & $<0.001$ & $14 \dagger+14=28$ \\
Br 1 Gy +LRT & 0.089 & $0.96 \pm 0.11$ & $<0.001$ & $4 \dagger+8=12$ \\
\hline
\end{tabular}

LRT, high-dose local radiotherapy; + plateau; survival $=1.0$.

The k-values in Table 1 varied up to nine-fold among treatment schemes. The medians decreased at 69, 30, 24, 16, 28 , and 12 months as the k-value increased. The medians are shown in Table 1 in the form of sums, where the first item is 
latent time, with survival $=1.0$. The feedback between speed $(\mathrm{k})$ and median $(\mathrm{m})$ is described by the following equation:

$$
\mathrm{m}=1.99 \mathrm{k}^{-0.75}
$$

(coefficient $\mathrm{R} \pm \mathrm{m}_{\mathrm{R}}=0.92 \pm 0.19$, and $p=0.009$ ).

\subsection{Relationship between $\boldsymbol{k}$ and Lymphopenia}

Table 2 illustrates the relationship between the clinical effect and mean lymphocyte concentration before and 1 month after beginning treatment.

Table 2. Exponential mortality rates $\left(k\right.$, month $\left.^{-1}\right)$ and mean lymphocyte concentration before and during 1 month after beginning treatment.

\begin{tabular}{|c|c|c|c|c|}
\hline \multirow{2}{*}{ Subgroups } & \multicolumn{2}{|c|}{ Lymphocytes $\left(\cdot 10^{9} / \mathrm{L}\right)$} & \multirow{2}{*}{ k, month m $^{-1}$} & \multirow{2}{*}{ Median (M), months } \\
\hline & $M \pm S E(n)$ before & $\mathrm{M} \pm \mathrm{SE}$ (n) during & & \\
\hline B 9 Gy & $1.07 \pm 0.082(28)$ & $0.75 \pm 0.1 \quad(106)^{* *}$ & 0.01 & 69 \\
\hline$A_{C P}$ & $1.6 \pm 0.11$ & $1.28 \pm 0.06(114)^{* *}$ & 0.026 & 30 \\
\hline $\mathrm{B}_{1 \mathrm{~Gy}}$ & $1.01 \pm 0.085(55)$ & $0.9 \pm 0.074(208)$ & 0.029 & 24 \\
\hline $\mathrm{Br}_{1 \mathrm{~Gy}}$ & $0.93 \pm 0.147(20)$ & $0.9 \pm 0.06$ & 0.043 & 16 \\
\hline $\mathrm{A}_{\mathrm{TP}}$ & $1.59 \pm 0.14$ & $1.63 \pm 0.071(142)$ & 0.051 & 28 \\
\hline \multirow[t]{3}{*}{$\mathrm{Br}_{1+} \mathrm{Gy} \mathrm{LRT}$} & $0.86 \pm 0.166(13)$ & $0.46 \pm 0.075(51)^{*}$ & 0.089 & 12 \\
\hline & \multicolumn{2}{|c|}{ Dependence $\mathrm{k}$ or $\mathrm{M}$ from $\mathrm{L}_{\text {before }}$} & NS, power function & NS, Ln-function \\
\hline & \multicolumn{2}{|c|}{ Dependence $\mathrm{k}$ or $\mathrm{M}$ from $\mathrm{L}_{\text {during }}$} & NS, power function & NS, Ln-function \\
\hline
\end{tabular}

NS, not significant; $* \mathrm{p}<0.05 ; * * 0.001>\mathrm{p}<0.01$; The types of function with maximal $\mathrm{R}^{2}$ are shown.

The moderate decrease in the lymphocyte concentration after 9 Gy of radiotherapy and $\mathrm{A}_{\mathrm{CP}}$ therapy coincided with the best therapeutic effect among all of the subgroups (Table 2). The lymphocytopenia was beyond moderate in subgroup $\left(\mathrm{Br}_{1 \Gamma \mathrm{p}+\mathrm{LRT}}\right)$ and coincided with the worst result. However, the Table 2 data do not reveal any association between lymphocyte concentration and treatment benefit.

Patients in the $A_{C P}$ and $A_{T P}$ subgroups with highest lymphocyte concentration before treatment (in $10^{9} / \mathrm{L}$ ) were divided into two components, one of which did not differ statistically from the other subgroups and was thus more suitable for the comparison: $1.09 \pm 0.064,2.1 \pm 0.18$ (CP), and $1.23 \pm 0.093,1.97 \pm 0,097$ (TP).



Fig. 2. Relationship between mortality rate ( $k$ ) and relative variation in mean blood lymphocyte concentration during the first month after beginning therapy.

$\mathrm{x}$, Relative change in mean cell concentration during the first month after beginning treatment $\left(\mathrm{C}_{\mathrm{after}}\right)$. These data were normalized to those before treatment $\left(\mathrm{x}=\mathrm{C}_{\mathrm{after}} / \mathrm{C}_{\text {before }}\right)$. Initial $\mathrm{C}_{\text {before }}\left(\right.$ in $\left.10^{9} / \mathrm{L}\right)$ values are shown as squares.

$\mathrm{y}$, exponential rate, $\mathrm{k}$, from Eq. 1.
The linear relationship is shown in the bottom panel.

The concentration $\mathrm{C}_{\text {before }}$ values after transforming the data of the subgroups are presented in Figure 2, and the values were not associated with the k-values:

$$
\mathrm{k}=-0.03 \operatorname{Ln}\left(\mathrm{C}_{\text {before }}\right)+0.046 ; \mathrm{R}=0.41 \pm 0.37 ; p=0.31, \mathrm{NS}
$$

Absolute values for the mean cell concentrations after therapy $\left(\mathrm{C}_{\mathrm{after}}\right)$ from left to right in Figure 2 are: $0.46 \pm 0.075$ $(\mathrm{n}=47), 0,75 \pm 0.072(\mathrm{n}=67), 1.01 \pm 0.054(\mathrm{n}=49), 1.67 \pm$ $0.097(\mathrm{n}=47), 0.9 \pm 0.074(\mathrm{n}=122), 1.99 \pm 0.074(\mathrm{n}=70)$, $0.92 \pm 0.06(\mathrm{n}=65)$, and $1.26 \pm 0.052 \cdot 10^{9}$ cells $/ \mathrm{L}(\mathrm{n}=72)$. These absolute values were not associated with the k-values:

$$
\mathrm{k}=-0.024 \operatorname{Ln}\left(\mathrm{C}_{\text {after }}\right)+0.04 ; \mathrm{R}=0.44 \pm 0.37 ; p=0.28, \mathrm{NS}
$$

Figure 2 confirms $(p<0,001)$ the linear relationship between the $\mathrm{k}$-value and relative lymphocyte concentration in the range of "moderate" lymphocytopenia $(>0.5 \times 109$ cells $/ \mathrm{L})$.

\section{Discussion}

The high inter-individual variability in the short-term recovery rate of hemato-lymphocytopoiesis after cytotoxic therapy has been reported [12]. Equation 5 do not confirm an obvious influence of the absolute lymphocyte concentration after therapy on the benefit of systemic treatment.

Our results indicate that the relative deviation of cells in patients receiving different therapies is necessary for treatment success and is quantitatively associated with the therapy. The least (best) monthly mortality rate $(\mathrm{k}=0.01$ month $^{-1}$ ) and maximally induced lymphocytopenia 0.7 (from $1.07 \pm 0.082$ to $(0.75 \pm 0.072) \times 10^{9}$ cells $\left./ \mathrm{L} ; \mathrm{p}=0.004\right)$ occurred after the LHBI total dose of 9 Gy (scheme B 9Gy). In contrast, the maximum $\mathrm{k}$ value $\left(0.0583 \mathrm{month}^{-1}\right)$ was associated with an relative increasing mean cell concentration 1.16 (from $1.09 \pm 0.064$ to $(1.26 \pm 0.052) \times 10^{9}$ 
cells/L; $p=0.04$ (scheme ATP). Both extremes were within the limits of the linear dependence shown in Figure 2, which confirms gradual improvement in the result in accordance with the relative increase in lymphocytopenia $(\mathrm{p}<0.001)$. The two high initial values $\left(1.97\right.$ and $2.1 \cdot 10^{9}$ cells/L) indicate that the results were defined by the degree of relative suppression in cell number, rather than the absolute value.

Patients with severe lymphocytopenia (below the critical moderate level of $0.5 \times 10^{9}$ cells $/ \mathrm{L}$ ) remained uncured (highest $\mathrm{k}$-value $=0.089$ ), as shown by the left point beyond linear dependence in Figure 2. This could be classified as a hematopoietic form of acute radiation syndrome [13], which represents an additional mortality risk because of myelosuppression overload independent of the malignancy process.

The initial cell concentration did not affect ACP but was essential for ATP (Fig. 2) The treatment result of $2.110^{9}$ cells $/ \mathrm{L}$ in scheme ATP $(\mathrm{k}=0.0382$ month-1) was better $(\mathrm{k}=0.0583$ month -1$)$ at a reliably smaller initial concentration of $1.09 \pm$ $0.06410^{9}$ cells $/ \mathrm{L}(\mathrm{p}<0.001)$, suggesting that the steroid pretreatment included in scheme ATP had an effect. Steroids are recommended [1] for more severe lymphocytopenia $\left(<0.5 \times 10^{9}\right.$ cells/L) than that of our cases. Steroids inhibit the effect of paclitaxel on human ovarian carcinoma [14]. At "subnormal" levels of about $110^{9}$ cells/L, as in our cases, steroid pretreatment increases the concentration of cells to $20 \%$ to $30 \%$ above the initial level within 1 day after a short-term decrease [15]. Thus, two reliable consequences of steroid stimulation were observed in subgroup ATP compared with subgroup ACP: the longer initial 100\% survival period (14 vs. 3 months) (Table 1) and the subsequent acceleration in the mortality rate $(\mathrm{k}=0.0583$ and 0.0382 months $^{-1}$ vs. $\mathrm{k}=0.0271$ and 0.0215 months $^{-1}$ ) (Fig. 2).

The influence of such early (within 1 month) relative deviations in lymphocytopenia on long-term treatment results is predictive of the so-called performance status of patients before treatment [16]. This is because induced lymphocytopenia reflects the pathophysiological status of hematopoiesis that is most injurable the system, which controls overall stability and viability. The long-term influence of early lymphocytopenia on the k-values of the subgroups during 5 years (Fig. 2) can be explained as follows. Complete recovery of initial blood lymphocyte concentration takes at least 1 year, even after a single nonlethal dose of cytotoxic therapy [9]. Thus, the inverse relationship between relative short-term lymphocytopenia within the first month of treatment and the long-term mortality rate during the subsequent 5-year period (Fig. 2) does not support the idea of immune protection against malignant progression. In contrast, it corresponds to the idea of trophic/morphogenic support of tissue regeneration, regardless of its genesis by circulating mononuclear cells. The validity of such a morphogenic function of the hemato-lymphocytopoietic system has been assessed in some patients $[17,18]$ and dogs with neoplasm exposed to low doses of ionizing radiation during their entire life [19]. Angiogenesis is a fundamental process that affects wound healing, regeneration, vascularization of ischemic tissue, and tumor development and metastasis. The total fraction of lymphocytes in the blood includes minor mononuclear species, such as angiogenic hematopoietic stem cells and angiogenic T-lymphocytes, which support the development of microvessels in normal, quasi-embryonic, and malignant tissues [20, 21, 22]. Even "therapeutic" myelosuppression reduces temporarily the number of hematopoietic stem cells, and some cells are redirected from the tumor to regenerate bone marrow and other normal tissues $[9,23,24]$. These findings clarify the crucial question of why myelo-immunosuppression is inseparable from the benefits of cytotoxic therapy [25, 26]. The alternative concept of the morphogenic functions of a special pool of circulating mononuclear cells opens the possibility for a better understanding of the therapeutic actions of systemic therapy on solid cancer compared with the traditional immune protection concept.

\section{Conclusion}

The inevitable side effects of systemic cytotoxic cancer therapy, such as massive lymphocytopenia, shed doubt on the existence of effective antineoplastic immunity. A reverse linear dependence between relative lymphocytopenia level and the exponential mortality rate of patients with advanced ovarian cancer was found after systemic chemo- or radiotherapy treatment. These data provide a logical background regarding the morphogenic function of some circulating mononuclear cells in relation to any proliferating tissues, including malignant ones. Further investigations are necessary to confirm the side effects caused by cytotoxic systemic treatment.

\section{References}

[1] U.S. Department of Health and Human Services, National Institute of Health, National Cancer Institute."Blood/bone marrow," in: Common terminology criteria for adverse events (CTCAE)/Version 3.0, AMGEN Oncology, p.4, August 2006. ctep.cancer.gov/.../electronic.../ctcaev3.pdf。

[2] G. Beretta, Cancer chemotherapy regimens. Milano, Italy, Farmitalia Carlo Erba, 1983. opac.sbn.it/.../opaclib.

[3] J. L. Liesveld, Ph. Rubin, and L.S. Constine, "Hematopoietic system", in: Adverse late effects of cancer treatment. V.2: Normal tissue specific sites and systems, Eds. Ph. Rubin, L. S. Constine, L. B. Marks, Heidelberg, Germany, Springer Verlag, 2014, pp. 623-656. doi: 10.1007/978-3-540-75863-1.

[4] M. Akiyama and Y. Kusunoki, "Immune function," in: Effects of A-bomb radiation on the human body, I. Shigematsu, C. Ito, N. Kamada, M. Akiyama, H. Sasaki, B. Harrison, Eds. Tokyo, Japan, Harwood academic publishers, Bunkodo Co.,1995, pp. 290-306.

[5] A. Shoutko and N. Shatinina, "Chronic cancer - could its be?," COHERENCE. International Journal of Integrated Medicine, 1998. 2. pp. 36-40. www.iaam.nl/coherence/msaima/2983.HTML. 
[6] A. N. Shoutko, L. P. Ekimova, M. J. Vasilyeva, and N. N. Shatinina, "Tissue factors involved in cancer induction", in: High level of natural radiation and radon areas:radiation dose and health effects, part 2, J. Peter, G. Schnider, A. Bayer, Eds., Bundesamt fur Strahlenscutz Schriften, 2002, Proceedings of 5 th international conference on high levels of natural radiation and radon areas held in Munich, Germany on September 4 to 7, 2000. pp. 467-470. www.gbv.de/dms/tibub.../347281052.pdf

[7] A. Shoutko, I. Akushevich, L. Ekimova, M. Karamullin, A. Yashin, "The terminal exhaustion of hematopoietic potentiality as universal cause of death," Abstracts book of 38th Annual Meeting of the European Radiation Research Society held in Stockholm, Sweden on September 5 to 9, 2010 , p. 187. www.docstoc.com/.../38th-Annual-Meeting-of-theEuropean-Radiation-...

[8] C. Drapeau, Cracking the stem cell code: demystifying the most dramatic scientific breakthrough of our times. Hillsboro, Or, Goodwill Books USA, Sutton Hart Press / 1st. ed., 2010. http://www.amazon.com/Cracking-Stem-Cell-CodeMiraculous/dp/098102095X

[9] W. Nothdurft, "Bone Marrow", in: Radiopathology of organs and tissues, E.Scherer, C. Streffer, and K.Trott, Eds., Berlin, Germany, Springer-Verlag, 1991, pp. 113-169. https://books.google.ru/books?isbn

[10] Curve fitting project - pdf.io, pp. 1-4. dynsys.uml.edu/tutorials/Regression.../curve_fit_proj_101905. pdf

[11] J. L. Loveland, (2011).Mathematical justification of introductory hypothesis tests and development of reference materials (M.Sc. (Mathematics). Utah State University, Retrieved April/2013. http://digitalcommons.usu.edu/cgi/viewcontent.cgi?article $=10$ $14 \&$ context $=$ gradreports

[12] F. Khalil, H. Cualing, J. Cogburn, and L. Miles, "The criteria for bone marrow recovery postmyelosuppressive therapy for acute myelogenous leukemia: a quantitative study," Arch Pathol Lab Med, vol. 131(8), pp. 1281-1289, August 2007. PMID: 17683190

[13] T. M. Fliedner D. and H. Graessle, "Hematopoietic cell renewal systems: mechanisms of coping and failing after chronic exposure to ionizing radiation," Radiat Environ Biophys, vol. 47(1), pp. 63-69, February 2008. doi:10.1007/s00411-007-0148-6

[14] W. J. Hou , J. H. Guan, Q. Dong, Y. H. Han, and R. Zhang, "Dexamethasone inhibits the effect of paclitaxel on human ovarian carcinoma xenografts in nude mice," Rev Med Pharmacol Sci, vol.17(21), pp. 2902-2908, Nov. 2013. PMID: 24254559

[15] M. H. Magee, R. A. Blum, C. D. Lates, and W. J. Jusko, "Pharmacokinetic/pharmacodynamic model for prednisolone inhibition of whole blood lymphocyte proliferation," Br J Clin Pharmacol, vol. 53(5), pp. 474-484, May 2002. doi: 10.1046/j.1365-2125.2002.01567.x PMCID: PMC1874371

[16] R. W. Jang, V. B. Caraiscos, N. Swami, S. Banerjee, E. Mak, E. Kaya, G. Rodin, J. Bryson, J. Z. Ridley, L. W. Le, and C. Zimmermann, "Simple prognostic model for patients with advanced cancer based on performance status," J of On Practice, vol. 10(5), pp. e335-e341, September 2014. doi: 10.1200/JOP.2014.001457

[17] A. Shoutko, L. Ekimova, V. Mus, and V. Sokurenko, "Fluctuations of CD34 cells number in blood of cancer patients during final year of life," Medical and Health Science Journal (MHSJ)/Acad. Publ. Platform, vol.13(4), pp. 7-13, December 2012 . academicpublishingplatforms.com/article.php?.

[18] A N. Shoutko and L P. Ekimova, "The impact of middle age on the viability of patients with nonmalignant and malignant diseases," Cancer Research Journal, vol. 2(6), pp. 114-120, December 2014. doi: 10.11648/j.crj.20140206.14

[19] A.N. Shoutko and L.P. Ekimova, "Abnormal tissue proliferation and life span variability in chronically irradiated dogs," Radiat Environ Biophys, vol. 53(1), pp. 65-72, March 2014. doi: 10.1007/s00411-013-0504-7

[20] J. Hur, H.-M. Yang, C.-H. Yoon, C.-S. Lee, K.-W. Park, J.-H. Kim, T.-Y. Kim, J.-Y. Kim, H.-J. Kang, I.-H. Chae, B.-H. Oh, Y.-B. Park, and H.-S. Kim, "Identification of a novel role of T cells in postnatal vasculogenesis. Characterization of endothelial progenitor cell colonies," Circulation, vol. 116(15), pp. 1671-1682, October 2007. PMID:17909106

[21] V. Cumar, A K Abbas, N Fausto, and J Astar, "Tissue renewal, regeneration, and repair," in: Robins and Cotran pathologic basis of disease, 8th edition by $\mathrm{V}$ Sounders Elsevier, Philadelphia, PA, USA, 2010, pp.79-110. http://www.us.elsevierhealth.com/media/us/samplechapters/97 81437707922/Chapter\%2003.pdf

[22] L. Zucco, Q. Zhang, M. A. Kuliszewski, I. Kandic, M. E. Faughnan, D. J. Stewart, M. J. Kutryk, "Circulating angiogenic cell dysfunction in patients with hereditary hemorrhagictelangiectasia," PLoS ONE, vol. 9(2), p. e89927, February 2014. doi: 10.1371/journal.pone.0089927. PMCID: PMC3934937

[23] A. N. Shutko, I. V. Akushevich, L. P. Ekimova, V. F. Mus, B. P. Sokurenko, L. E. Yurkova, and K. S. Matiurin, "The mechanism of the antitumor effect of total/subtotal radiotherapy with non-tumoricidal doses of radiation," Voprosy onkologii, 59(4), pp. 475-478, Okt-Dec 2013. PMID 24032222

[24] A. N. Shoutko and L. P. Ekimova, "Lymphocytopenia can contribute in common benefit of cytotoxic therapy of cancer," Inter-Medical, №3， pp. 5-13， September 2014. www.intermedical.ru/zhurnaly/17-zhurnal-1/meditsinskienauki; $\quad$ http://inter-medical.ru/files/Arhiv/2627.09.2014/inter3.pdf

[25] K. J. Propert and J. R. Anderson, "Assessing the effect of toxicity on prognosis: methods of analysis and interpretation," JCO, vol. 6, pp. 868-870, month 1988. http://jco.ascopubs.org/content/6/5/868.full.pdf

[26] K. S. Tewari, J.J. Java, T.A. Gatcliffe, M.A. Bookman, and B.J Monk, "Chemotherapy-induced neutropenia as a biomarker of survival in advanced ovarian carcinoma: an exploratory study of the gynecologic oncology group," Gynecol Oncol, vol.133(3), pp. 439-45, March 2014. PMID:24657300; doi: 10.1016/j.ygyno.2014.03.013. Epub 201420. 